Ophthalmologica

\title{
Laser Treatment in Diabetic Retinopathy
}

\author{
Aljoscha S. Neubauer Michael W. Ulbig \\ Department of Ophthalmology, Ludwig Maximilians University Munich, Munich, Germany
}

\section{Key Words \\ Diabetes · Laser therapy • Diabetic Retinopathy Study}

\begin{abstract}
Diabetic retinopathy is a leading cause of visual impairment and blindness in developed countries due to macular edema and proliferative diabetic retinopathy (PDR). For both complications laser treatment may offer proven therapy: the Diabetic Retinopathy Study demonstrated that panretinal scatter photocoagulation reduces the risk of severe visual loss by $>50 \%$ in eyes with high-risk characteristics. Panretinal scatter coagulation may also be beneficial in other PDR and severe nonproliferative diabetic retinopathy (NPDR) under certain conditions. For clinically significant macular edema the Early Treatment of Diabetic Retinopathy Study could show that immediate focal laser photocoagulation reduces the risk of moderate visual loss by at least $50 \%$. When and how to perform laser treatment is described in detail, offering a proven treatment for many problems associated with diabetic retinopathy based on a high evidence level.

Copyright $\odot 2007$ S. Karger AG, Basel
\end{abstract}

\section{Introduction}

Diabetic retinopathy is a leading cause of visual impairment and blindness in developed countries. Macular edema is the major cause of vision loss in diabetic pa- tients, while proliferative retinopathy is another common cause [1]. For both of these retinal complications of diabetes laser treatment can, if timely applied, greatly reduce the probability of vision loss. Of course, the other modifiable risk factors of disease progression have to be optimized in adjunction to any laser therapy, especially optimizing blood glucose control $[2,3]$ and tight blood pressure control [4].

\section{History of Laser Treatment}

While H.G. Wells foresaw the development of lasers in his book The War of the Worlds in 1897, it was not until 1960 that Maiman built the first working laser. A flash of light was used to deliver light energy to a ruby crystal. Due to 1 totally and 1 partially reflecting mirror at each end a light amplification by stimulated emission of radiation (LASER) device is obtained. The typical characteristics are monochromatic light, spatial coherence and a high density of electrons. Several different wavelengths have been and are being developed, including ruby (694 nm), argon green (514 nm), krypton (647 nm), Nd:YAG (1,064 and frequency doubled to $532 \mathrm{~nm})$, diode (810 nm), excimer (193 nm).

The previously used xenon light photocoagulator had been developed by the German ophthalmologist MeyerSchwickerath together with Littmann from Zeiss in the 1950s and made photocoagulation independent of sunlight and weather conditions. Its spot size was variable

\section{KARGER}

Fax +41613061234

E-Mail karger@karger.ch

www.karger.com
(C) 2007 S. Karger AG, Basel

$0030-3755 / 07 / 2212-0095 \$ 23.50 / 0$

Accessible online at:

www.karger.com/oph
Prof. Michael Ulbig

Department of Ophthalmology, Ludwig Maximilians University

Mathildenstrasse 8, DE-80336 München (Germany)

Tel. +49 895160 3811, Fax +498951605160

E-Mail Michael.Ulbig@med.uni-muenchen.de 
ranging from $3^{\circ}$ to $8^{\circ}$ (i.e. minimum spot size approx. $>500 \mu \mathrm{m}$ ) and the burns had greater power than laser burns, therefore usually yielding full thickness burns. In contrast, the laser effects include (depending on laser type, tissue characteristics and settings) photochemical effects, photoirradiation, photocoagulation and photodisruption. Lasers became available for ophthalmologic applications in the late 1960 s and became more frequently used in the 1970s. Coagulation treatment of the retina for diabetic retinopathy became a standard of care since the Diabetic Retinopathy Study (DRS) results were published in the late 1970s. It showed a great reduction of severe vision loss in high-risk proliferative disease for both xenon and argon laser photocoagulation [5].

\section{Panretinal Laser Treatment for Proliferative Diabetic Retinopathy}

The DRS enrolled 1,742 patients, 876 of whom were randomized to the argon group and 875 to the xenon group [6]. Argon photocoagulation involved the placement of $800-1,600$ burns with $500 \mu \mathrm{m}$ diameter or 500 1,000 burns with $1,000 \mu \mathrm{m}$ diameter, both at $0.1 \mathrm{~s}$ of duration. The areas treated included the retina to or beyond the vortex veins in 1 or 2 sessions, also covering neovascularization of the optic disc (NVD), which is no longer typically performed today. The primary endpoint of the study was a visual acuity of $<5 / 200$ on 2 consecutive visits 4 months apart. After 3 years argon laser coagulation could decrease the rate of severe visual loss to $13.3 \%$, and xenon coagulation to $18.5 \%$, while untreated eyes had $26.4 \%$. Thus at least a $50 \%$ reduction in the rate of severe visual loss could be demonstrated for panretinal laser treatment, which was maintained during a 5-year follow-up period [7]. The harmful effects of photocoagulation were more pronounced for xenon coagulation than for argon laser coagulation and included a reduction of visual acuity due to treatment and loss of peripheral visual field. For laser treatment a decrease by $\geq 1$ lines occurred in $10 \%$ and a mild constriction of visual fields in 5\% [7]. Macular edema, which may be exacerbated by panretinal photocoagulation and will be discussed in detail later, was not evaluated in the DRS. Finally the socalled high-risk characteristics, for which the benefits of peripheral coagulation outweigh the risks, were defined as $[7,8]$ :

$1 \quad$ NVD $\geq 1 / 4$ to $1 / 3$ disc area in extent

2 New vessels on or within 1 disc diameter of the optic disc (NVD)
3 Any new vessels within 1 disc diameter of the optic disc and associated with vitreous or preretinal hemorrhage

4 Proliferation elsewhere at least $1 / 2$ disc area in size and associated with vitreous or preretinal hemorrhage

The risk of severe visual loss was $26 \%$ for eyes exhibiting these high-risk characteristics (at least 3 of 4 signs) as compared to $7 \%$ in proliferative diabetic retinopathy (PDR) without those characteristics after 2 years [9]. Photocoagulation reduced this risk by $50 \%$. Therefore the DRS recommends panretinal laser treatment for (1) eyes with new vessels and preretinal or vitreous hemorrhage; and (2) eyes with new vessels on or within 1 disc diameter of the optic disc (NVD) $\geq 1 / 4$ to $1 / 3$ disc area in extent (with or without preretinal or vitreous hemorrhage) [7]. It was not able to give recommendations on earlier stages such as severe nonproliferative patients.

The current international clinical diabetic retinopathy disease severity scale distinguishes 5 levels of retinopathy [10]: (0) no apparent retinopathy; (1) mild nonproliferative diabetic retinopathy (NPDR, only microaneurysms); (2) moderate NPDR; (3) severe NPDR (including any of: $>20$ intraretinal hemorrhages in each quadrant, venous beading in $\geq 2$ quadrants, intra-retinal microvascular abnormalities (IRMA) in $\geq 1$ quadrant, but no proliferations), and (4) proliferative retinopathy (defined by neovascularization and/or vitreous/preretinal hemorrhage). The subgroup with high-risk characteristics has been described by the DRS above.

A summary of current treatment recommendations for laser therapy using this disease scale [11-13] is given in figure 1. In supplementation to the DRS criteria it is recommended at a high evidence level [9] to perform panretinal laser coagulation for PDR, NVD, proliferation elsewhere $>1 / 2$ disc area, vitreous/preretinal hemorrhage and neovascularization of the iris under certain conditions. Additionally, for severe NPDR scatter laser coagulation may be indicated in some cases (see fig. 1). Laser treatment should be performed over a period of 4-6 weeks at $500 \mu \mathrm{m}$ spot size, spaced 0.5 burn widths from each other with 0.1-0.2 s of duration (for green lasers). Intensity should be regulated so that mild white bleaching is obtained, the treatment area reaches from the temporal arcade to the equator and up to 2 disc diameters temporal from the macular center. Around the optic disc some space (e.g. 1 disc diameter) should be spared (see fig. 2) to avoid central visual field defects [14]. 
Fig. 1. Algorithm for panretinal scatter coagulation of the retina [11-13]. For details of the used classification see text. A macular edema must be assessed separately (see text and fig. 2). Type 2 diabetes (older patients) may benefit more from early scatter photocoagulation [60].

Fig. 2. Illustration of treatment area for panretinal scatter photocoagulation on widefield imaging (Optomap, Optos, Dunfermline, Fife, Scotland, UK). For details please see text.
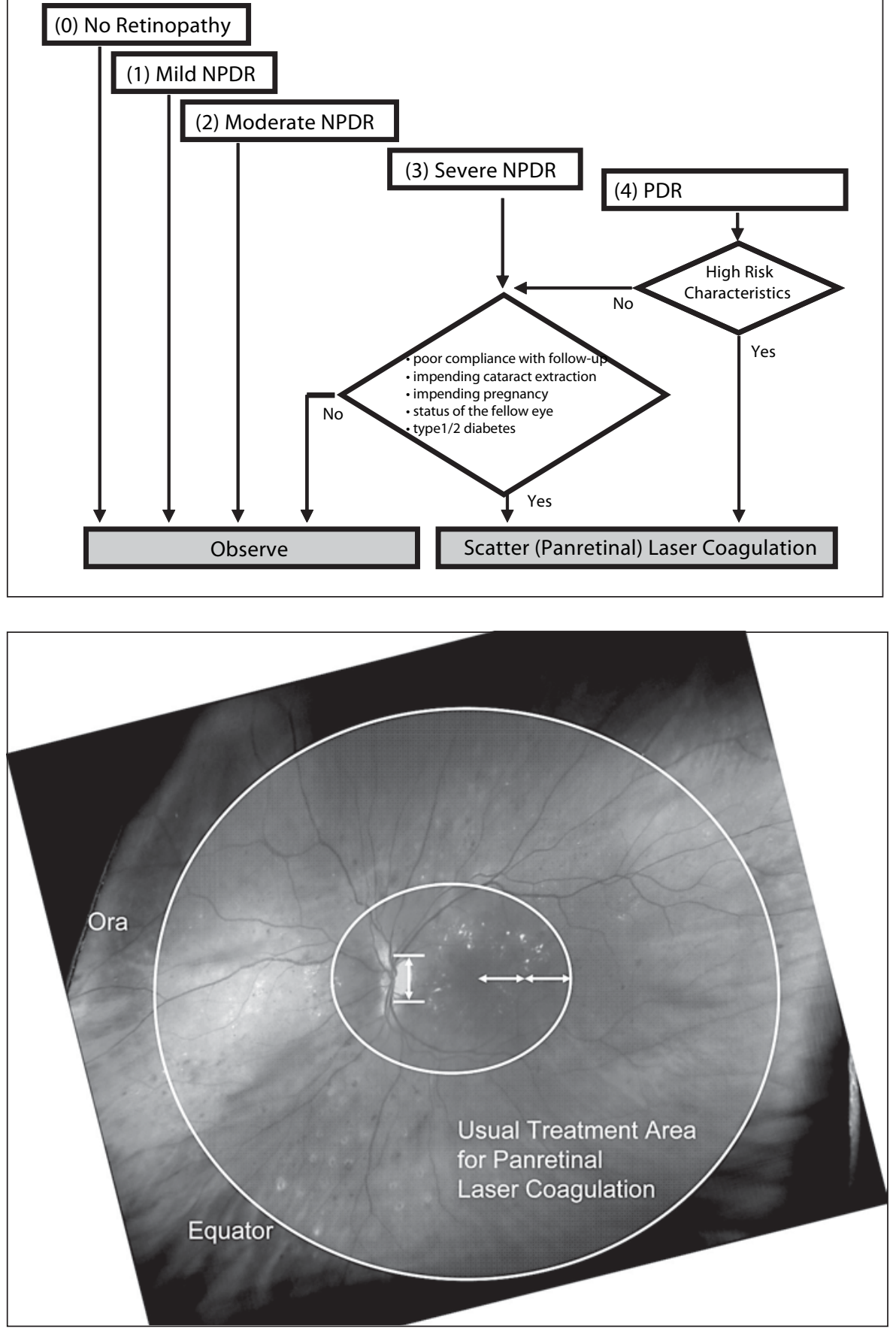

\section{Laser Treatment of Macular Edema}

Macular edema is responsible for a major part of visual impairment associated with diabetic retinopathy [1]. Correct and timely treatment is of vital importance to avoid severe visual loss. The Early Treatment of Diabetic Retinopathy Study (ETDRS) formed the basis of current treatment regimens by laser. The multicenter randomized study was designed to investigate the effect of photocoagulation and aspirin treatment in patients with 
Fig. 3. Algorithm for laser treatment for macular edema. Please note that proliferative disease must be assessed separately as discussed in the text and shown in figure 1. $\mathrm{CSME}=$ clinically significant macular edema.

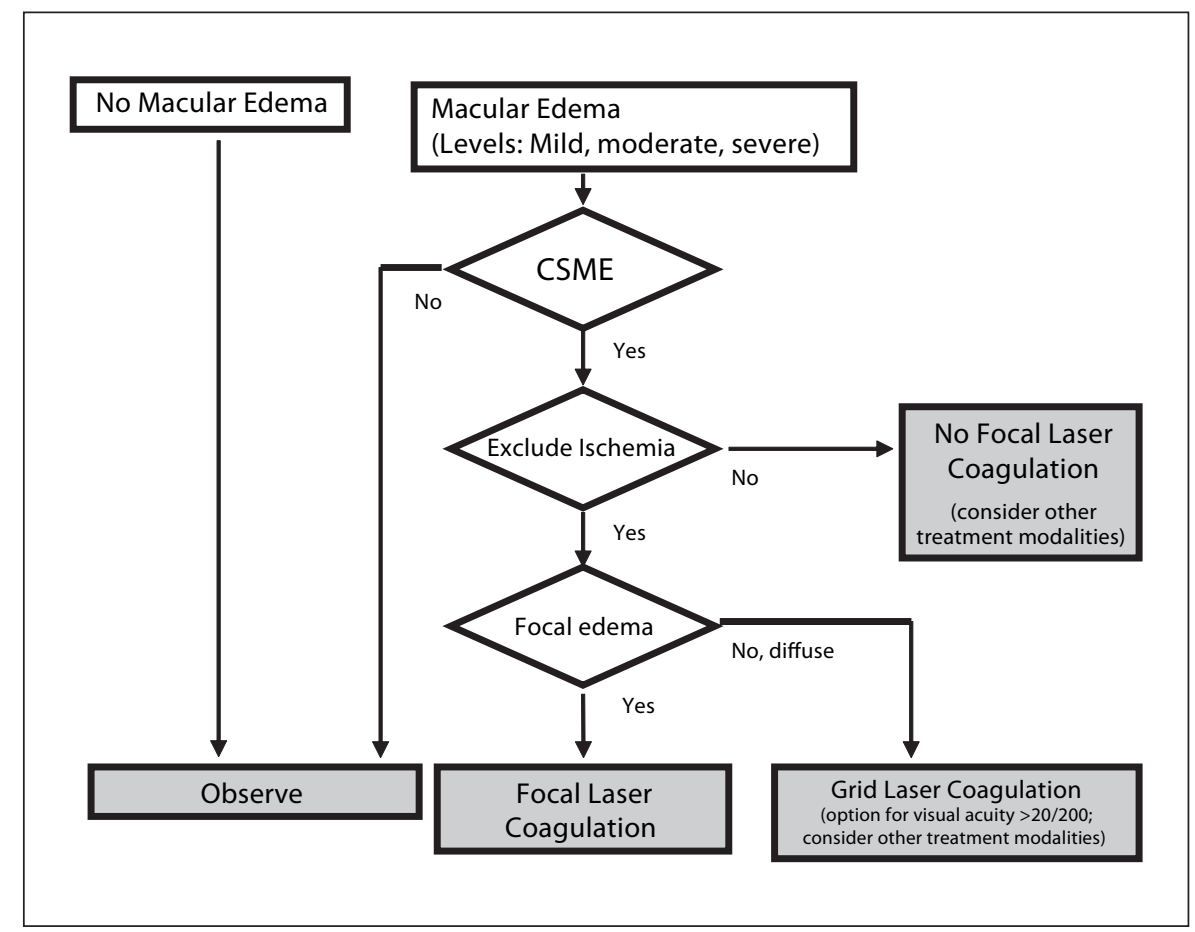

NPDR and early proliferative retinopathy. It enrolled a total of 3,711 patients between 1980 and 1985 who met the following criteria: (1) no macular edema with visual acuity $>20 / 40$ and (2) macular edema with visual acuity $>20 / 200$.

As one result the ETDRS showed that the randomized intake of $650 \mathrm{mg}$ aspirin per day did not alter the clinical course [15]. It also investigated as a second question when in the course of diabetic retinopathy panretinal laser coagulation is most effective. To answer both these questions, patients without macular edema were randomized to either early (mild or full) scatter photocoagulation or deferral. Eyes with macular edema were randomized to either deferral or immediate focal or immediate panretinal plus follow-up focal photocoagulation. Full scatter photocoagulation was defined as in the DRS, and mild scatter photocoagulation consisted of $500-\mu \mathrm{m}$ spots spaced 1 burn width apart from each other. For eyes without macular edema, no benefit resulted from immediate photocoagulation (either mild or full scatter, focal where needed) to prevent moderate or severe visual loss. For eyes with macular edema and more severe retinopathy a small reduction of the risk for severe visual loss was found with early photocoagulation [16]. However, there was an increased risk of moderate visual loss in the treatment group after 6 weeks, which after 1 year reversed. The least visual loss was in the group treated by mild scatter to- gether with immediate focal photocoagulation [16]. This supports the algorithm given in figures 1 and 3 regarding timing of scatter photocoagulation and further justifies photocoagulation in non-high-risk characteristic eyes [16].

The third and main question to be answered by the ETDRS was the efficacy of laser treatment for macular edema (fig. 3). Macular edema was defined as: (1) thickening of the retina at or within $500 \mu \mathrm{m}$ of the center of the macula; (2) hard exudates at or within $500 \mu \mathrm{m}$ of the center of the macula, if associated with thickening of adjacent retina, and (3) a zone of retinal thickening $\geq 1$ disc area, any part of which is within 1 disc diameter of the center of the macula.

Any of these 3 criteria defined clinically significant macular edema (CSME, see fig. 4). Focal laser treatment consisted of 50- to $100-\mu \mathrm{m}$ laser burns of $0.05-0.1 \mathrm{~s}$ duration directed at microaneurysms between 500 and 3,000 $\mu \mathrm{m}$ from the macular center achieving whitening around or (if $>40 \mu \mathrm{m}$ ) color change of the microaneurysm. Treatment closer than $300 \mu \mathrm{m}$ from the fovea was not recommended (rarely $<500 \mu \mathrm{m}$ ). Diffuse leakage or nonperfusion were treated in a more indirect way focused at the retinal pigment epithelium: within 2 disc areas of the fovea a grid pattern with 50 - to $200-\mu$ m spots, spaced 1 burn width apart, was applied [17]. Figure 4 illustrates the size relationships. Moderate visual loss, defined as $>15$ 


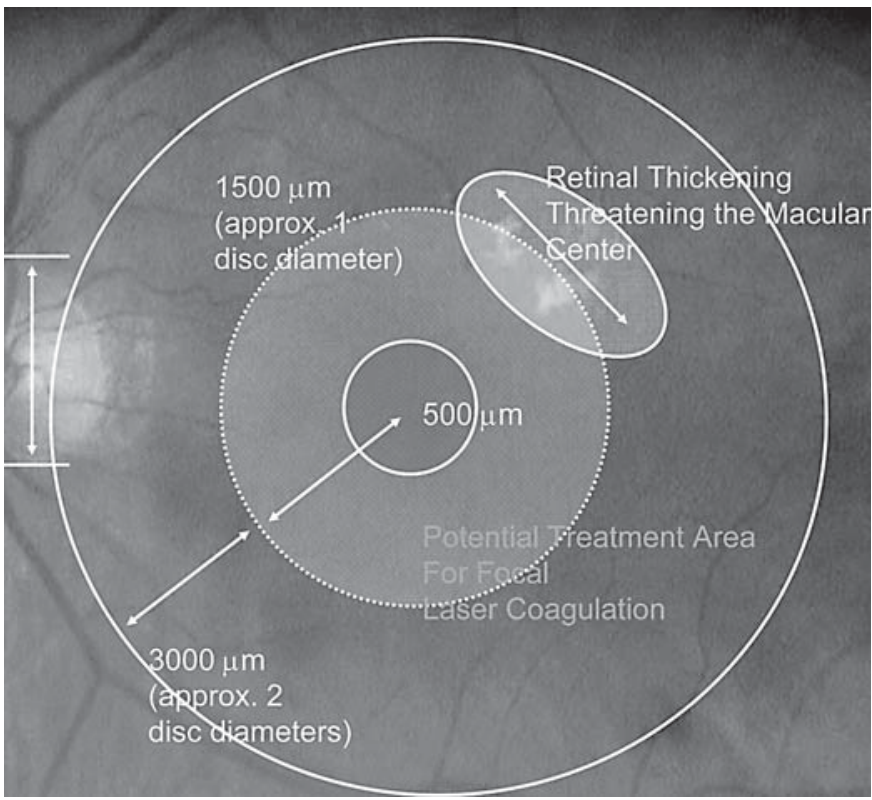

Fig. 4. Illustration of treatment area for focal (and grid) photocoagulation for CSME. For details please see text and figure 3 .

letters (i.e. $\geq 3$ lines), was the primary endpoint. In brief, the ETDRS could show that immediate focal laser coagulation in eyes with CSME could reduce the percentage of eyes with moderate visual loss by at least $50 \%$. This effect was maintained over follow-up time, for example after 3 years $12 \%$ as opposed to untreated $24 \%$ was achieved [16]. However, visual improvement was observed in a minority of cases; for the majority of cases the goal of photocoagulation is to stabilize visual acuity. Therefore patients with good visual acuity and CSME should definitely be considered for treatment [18]. On average 3-4 treatment sessions 2-4 months apart were needed [19]. The side effects of focal photocoagulation include an initial decrease in central vision and rarely subretinal fibrosis with choroidal neovascularization. The development of subretinal fibrosis is associated with the degree of subretinal exudates and only $8 \%$ were directly attributable to laser coagulation [20]. Paracentral scotomas may be noted by the patient with burns close to the macular center, especially when confluent [21].

\section{Diffuse Macular Edema}

In focal macular edema well-defined focal areas of leakage with retinal thickening are seen. As described above for the ETDRS, treatment may consist of either direct treatment of leaking microaneurysms or indirect treatment of the retinal pigment epithelium, usually ap- plied in a more grid-like fashion directed towards thickened areas. In contrast, in diffuse macular edema, leakage occurs diffusely from the retinal capillaries. Retinal microaneurysms, hard exudates and retinal hemorrhages tend to be few in number and small in size. Subtypes include central diffuse edema caused by leakage of the capillaries immediately adjacent to the foveal arcade and generalized diffuse edema [22]. In the latter a more widespread retinal thickening is observed across the posterior pole. Laser treatment has been evaluated using 100 - to 200- $\mu \mathrm{m}$ spot size and just threshold burns at the level of the pigment epithelium. Usually spots are applied spaced 1 spot size apart and 100-200 burns are required. The socalled 'grid' pattern depends on the pattern of leakage and may be performed circularly around the macular center (including the papillomacular bundle). Visual acuity $<20 / 200(0.1)$ is a contraindication for grid laser treatment $[11,12]$. The results of such treatment are contradictory $[23,24]$ and not of high evidence. Other treatment modalities such as pars plana vitrectomy [25] or different medical treatment options $[26,27]$ may be more promising.

\section{Ischemic Macular Edema}

While the accompanying edema may be variable, central ischemia is characterized by a loss of foveal capillaries/capillary nonperfusion. The clinical diagnosis is difficult, while fluorescein angiography shows an enlarged foveal avascular zone (i.e. $>500 \mu \mathrm{m}$ diameter) $[12,28,29]$. An example is shown in figure 5 . Laser therapy should not be applied if significant ischemia exists [22]. The complete algorithm for laser treatment of macular edema is given in figure 3.

\section{Coexistent Macular Edema and Proliferative Disease}

When scatter photocoagulation is to be carried out in eyes with coexisting CSME, there is evidence that first performing focal laser treatment may be beneficial. Both the DRS and ETDRS showed that full scatter photocoagulation may exacerbate macular edema leading to moderate visual loss [16]. This effect was quantified later [30]. The ETDRS could also show some advantage for immediate focal as compared to delayed focal coagulation together with panretinal laser therapy. Therefore it is advisable to first perform focal before panretinal photocoagulation. In cases with high-risk PDR simultaneous focal and scatter photocoagulation should be performed $[11,13]$. 


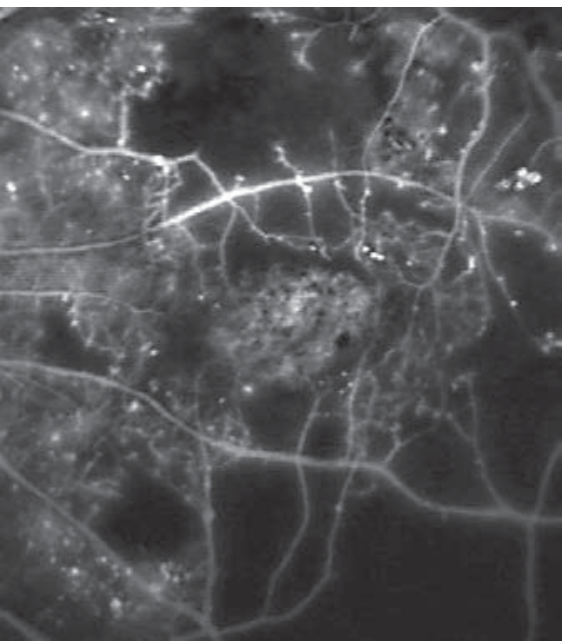

Fig. 5. Illustration of severe macular capillary dropout, i.e. macular ischemia. Focal laser coagulation should be avoided in such cases.

\section{Cataracts}

Various studies suggest that diabetic retinopathy, especially macular edema, may progress following cataract surgery $[9,31,32]$. Therefore, if the ocular media are clear enough, necessary laser therapy should be performed preoperatively. If this is impossible due to media opacities, re-evaluation and necessary therapy should be performed as soon as possible [11]. Regarding the implanted intraocular lens it is important to choose a model with a large optical zone facilitating further photocoagulation. Silicone material should definitely be avoided, since in the case of vitrectomy, especially with silicone oil, precipitates will occur [33].

\section{Laser Therapy for Subhyaloidal Hemorrhage}

In case of dense subhyaloidal hemorrhage located at the macular center disrupting the inner limiting membrane by an Nd:YAG laser [34] or green laser [35] may allow the blood to dissolve in the vitreous and be absorbed much faster. Panretinal laser treatment should be performed beforehand to avoid unnecessary delays. Complications of the method include macular hole formation and retinal detachment [36]. Other treatment options such as vitrectomy should also be considered in such cases.

\section{Diode Laser Treatment}

The diode laser is widespread due to its ease of maintenance, small size and lower costs. Due to its wavelength of $810 \mathrm{~nm}$ the biologic properties are different from other wavelengths such as the green lasers. Especially more profound effects of the diode laser in the choroid are known, which may be more painful for the patient during application. Regarding the effectiveness of avoiding progression of PDR no differences exist $[37,38]$. On the other hand functional parameters such as color contrast sensitivity or pattern electroretinograms after panretinal photocoagulation may be more in favor of diode laser treatment [39], while expansion of laser spots over time appears to be more likely with the longer wavelength of the diode laser [40].

Regarding macular edema, gentle threshold diode laser coagulation is suitable for focal laser therapy [41], although some studies suggest that it may be to some degree less effective than green laser wavelengths [42]. Subthreshold treatment minimizes damage but is to some extent less effective in promoting resolution of edema, though the difference was not significant [43]. Micropulsed application of subthreshold diode laser burns may increase its effectiveness $[44,45]$.

\section{Objective Retinal Thickness Measurements}

While the ETDRS used stereoscopic clinical examination and stereo fundus photographs to define macular changes [46, 47], over the last decade much more sensitive methods have become available to quantify retinal thickness objectively. Optical coherence tomography (OCT, Carl Zeiss Meditec, Jena, Germany) has rapidly become a standard method of analyzing macular changes [48] offering high resolution cross-section images. OCT and another instrument, the retinal thickness analyzer (Talia Technology, Neve-Ilan, Israel) having less resolution, can reliably detect small increases of retinal thickness of at least 20-40 $\mu \mathrm{m}$ [49-51]. Stereoscopic fundus examination usually only detects retinal thickening of approximately $100 \mu \mathrm{m}$ [52]. The new objective methods have been shown to be superior to clinical examination for investigating the extent of diabetic macular edema $[53,54]$. By these means it could also be shown that non-clinically significant retinal thickening occurs in most diabetic patients even in the absence of visible retinopathy [55]. This raises the question whether treatment of nonclinically significant ('subclinical') macular edema may 
be indicated under certain conditions - no such groups had been identified with the methods used in the ETDRS [16]. On the other hand methods like OCT and retinal thickness analyzer offer sensitive tools to follow changes in retinal thickness objectively, which allows better assessment of treatment success of e.g. focal laser treatment. The OCT can also identify membranes and vitreomacular traction [56,57], cases in which pars plana vitrectomy might be more beneficial than other treatment modalities $[25,58,59]$.

\section{Conclusions}

Laser therapy remains the main treatment modality for diabetic retinopathy. The DRS demonstrated that panretinal scatter photocoagulation reduced the risk of severe visual loss by $>50 \%$ in eyes with high-risk characteristics. It may also be beneficial in other PDR and severe NPDR under certain conditions. The ETDRS could show that immediate focal laser photocoagulation reduced the risk of moderate visual loss for CSME by at least $50 \%$. Usually several treatment sessions are required. In cases of both PDR and CSME, first the macula should be addressed unless high-risk characteristics warrant simultaneous panretinal treatment.

In summary, laser treatment offers proven treatments for many problems associated with diabetic retinopathy at a high evidence level. However, for certain situations such as macular ischemia, tractive components, severe proliferations and maybe diffuse macular edema other treatment modalities may be more beneficial. Surgery is definitely indicated for some situations and recently emerging medical therapies offer a variety of new approaches, which alone or in adjunction with laser therapy may help to further improve the outcome of treating diabetic retinopathy. However, their value still has to be proven at the same high level of evidence as that which exists for laser therapy.

\section{References}

1 Klein R, Klein BE, Moss SE: Visual impairment in diabetes. Ophthalmology 1984;91: $1-9$.

2 The relationship of glycemic exposure (HbA1c) to the risk of development and progression of retinopathy in the diabetes control and complications trial. Diabetes 1995; 44:968-983.

3 The effect of intensive diabetes treatment on the progression of diabetic retinopathy in insulin-dependent diabetes mellitus. The Diabetes Control and Complications Trial. Arch Ophthalmol 1995;113:36-51.

4 Tight blood pressure control and risk of macrovascular and microvascular complications in type 2 diabetes: UKPDS 38. UK Prospective Diabetes Study Group. BMJ 1998;317: 703-713.

5 Photocoagulation treatment of proliferative diabetic retinopathy: the second report of diabetic retinopathy study findings. Ophthalmology 1978;85:82-106.

6 Preliminary report on effects of photocoagulation therapy. The Diabetic Retinopathy Study Research Group. Am J Ophthalmol 1976;81:383-396.

7 Photocoagulation treatment of proliferative diabetic retinopathy: clinical application of Diabetic Retinopathy Study (DRS) findings, DRS Report Number 8. The Diabetic Retinopathy Study Research Group. Ophthalmology 1981;88:583-600.
8 Four risk factors for severe visual loss in diabetic retinopathy. The third report from the Diabetic Retinopathy Study. The Diabetic Retinopathy Study Research Group. Arch Ophthalmol 1979;97:654-655.

9 Indications for photocoagulation treatment of diabetic retinopathy: Diabetic Retinopathy Study Report No 14. The Diabetic Retinopathy Study Research Group. Int Ophthalmol Clin 1987;27:239-253.

10 Wilkinson CP, Ferris FL 3rd, Klein RE, Lee PP, Agardh CD, Davis M, Dills D, Kampik A, Pararajasegaram R, Verdaguer JT: Proposed international clinical diabetic retinopathy and diabetic macular edema disease severity scales. Ophthalmology 2003;110:16771682 .

11 Initiativgruppe Früherkennung diabetischer Augenerkrankungen (IFdA): Diagnostik, Therapie und Verlaufskontrolle der diabetischen Retinopathie und Makulopathie (Leitlinie der DDG). 2004. http://www.dieifda.de/downloads/DDGLeitlinie2004.pdf.

12 Initiativgruppe Früherkennung diabetischer Augenerkrankungen (IFdA): Stadieneinteilung und Therapie der diabetischen Retinopathie und Makulopathie. 2001. http:// www.die-ifda.de/html/aerzte/bildindex aerzte.html.

13 American Academy of Ophthalmology Preferred practice pattern: diabetic retinopathy. 2003. http://www.aao.org/education/ library/ppp/dr_new.cfm.
14 Davies N: Altering the pattern of panretinal photocoagulation: could the visual field for driving be preserved? Eye 1999;13:531-536.

15 Chew EY, Klein ML, Murphy RP, Remaley NA, Ferris FL 3rd: Effects of aspirin on vitreous/preretinal hemorrhage in patients with diabetes mellitus. Early Treatment Diabetic Retinopathy Study report No 20. Arch Ophthalmol 1995; 113:52-55.

16 Early photocoagulation for diabetic retinopathy. ETDRS report number 9. Early Treatment Diabetic Retinopathy Study Research Group. Ophthalmology 1991;98:766-785.

17 Treatment techniques and clinical guidelines for photocoagulation of diabetic macular edema. Early Treatment Diabetic Retinopathy Study Report Number 2. Early Treatment Diabetic Retinopathy Study Research Group. Ophthalmology 1987;94:761-774.

18 Ferris FL 3rd, Davis MD: Treating 20/20 eyes with diabetic macular edema. Arch Ophthalmol 1999;117:675-676.

19 Focal photocoagulation treatment of diabetic macular edema: relationship of treatment effect to fluorescein angiographic and other retinal characteristics at baseline - ETDRS report No. 19. Early Treatment Diabetic Retinopathy Study Research Group. Arch Ophthalmol 1995;113:1144-1155.

20 Lewis H, Schachat AP, Haimann MH, Haller JA, Quinlan P, von Fricken MA, Fine SL, Murphy RP: Choroidal neovascularization after laser photocoagulation for diabetic macular edema. Ophthalmology 1990;97: 503-510; discussion 510-501. 
21 Schatz H, Madeira D, McDonald HR, Johnson RN: Progressive enlargement of laser scars following grid laser photocoagulation for diffuse diabetic macular edema. Arch Ophthalmol 1991;109:1549-1551.

22 Hamilton AMP, Ulbig MW, Polkinghorne P: Management of Diabetic Retinopathy. London, BMJ Publishing Group, 1996.

23 Lee CM, Olk RJ: Modified grid laser photocoagulation for diffuse diabetic macular edema: long-term visual results. Ophthalmology 1991;98:1594-1602.

24 Ladas ID, Theodossiadis GP: Long-term effectiveness of modified grid laser photocoagulation for diffuse diabetic macular edema. Acta Ophthalmol (Copenh) 1993;71: 393-397.

25 Gandorfer A, Messmer EM, Ulbig MW, Kampik A: Resolution of diabetic macular edema after surgical removal of the posterior hyaloid and the inner limiting membrane. Retina 2000;20:126-133.

26 Jonas JB, Kreissig I, Sofker A, Degenring RF: Intravitreal injection of triamcinolone for diffuse diabetic macular edema. Arch Ophthalmol 2003;121:57-61.

27 Xu X, Zhu Q, Xia X, Zhang S, Gu Q, Luo D: Blood-retinal barrier breakdown induced by activation of protein kinase $C$ via vascular endothelial growth factor in streptozotocininduced diabetic rats. Curr Eye Res 2004;28: 251-256.

28 Classification of diabetic retinopathy from fluorescein angiograms. ETDRS report number 11. Early Treatment Diabetic Retinopathy Study Research Group. Ophthalmology 1991;98:807-822.

29 Arend O, Wolf S, Harris A, Reim M: The relationship of macular microcirculation to visual acuity in diabetic patients. Arch Ophthalmol 1995;113:610-614.

30 Shimura M, Yasuda K, Nakazawa T, Kano T, Ohta S, Tamai M: Quantifying alterations of macular thickness before and after panretinal photocoagulation in patients with severe diabetic retinopathy and good vision. Ophthalmology 2003;110:2386-2394

31 Benson WE, Brown GC, Tasman W, McNamara JA, Vander JF: Extracapsular cataract extraction with placement of a posterior chamber lens in patients with diabetic retinopathy. Ophthalmology 1993;100:730738.

32 Jaffe GJ, Burton TC, Kuhn E, Prescott A, Hartz A: Progression of nonproliferative diabetic retinopathy and visual outcome after extracapsular cataract extraction and intraocular lens implantation. Am J Ophthalmol 1992;114:448-456.

33 Hainsworth DP, Chen SN, Cox TA, Jaffe GJ: Condensation on polymethylmethacrylate, acrylic polymer, and silicone intraocular lenses after fluid-air exchange in rabbits. Ophthalmology 1996;103:1410-1418.

34 Gabel VP, Birngruber R, Gunther-Koszka H, Puliafito CA: Nd:YAG laser photodisruption of hemorrhagic detachment of the internal limiting membrane. Am J Ophthalmol 1989; 107:33-37.
35 Kroll P, Busse H: Therapy of preretinal macular hemorrhages. Klin Monatsbl Augenheilkd 1986;188:610-612.

36 Ulbig MW, Mangouritsas G, Rothbacher HH, Hamilton AM, McHugh JD: Long-term results after drainage of premacular subhyaloid hemorrhage into the vitreous with a pulsed Nd:YAG laser. Arch Ophthalmol 1998;116:1465-1469.

37 Ulbig MW, Hamilton AM: Comparative use of diode and argon laser for panretinal photocoagulation in diabetic retinopathy. Ophthalmologe 1993;90:457-462.

38 Bandello F, Brancato R, Trabucchi G, Lattanzio R, Malegori A: Diode versus argongreen laser panretinal photocoagulation in proliferative diabetic retinopathy: a randomized study in 44 eyes with a long followup time. Graefes Arch Clin Exp Ophthalmol 1993;231:491-494.

39 Ulbig MR, Arden GB, Hamilton AM: Color contrast sensitivity and pattern electroretinographic findings after diode and argon laser photocoagulation in diabetic retinopathy. Am J Ophthalmol 1994;117:583-588

40 Maeshima K, Utsugi-Sutoh N, Otani T, Kishi S: Progressive enlargement of scattered photocoagulation scars in diabetic retinopathy. Retina 2004;24:507-511.

41 Akduman L, Olk RJ: Diode laser (810 nm) versus argon green $(514 \mathrm{~nm})$ modified grid photocoagulation for diffuse diabetic macular edema. Ophthalmology 1997;104:14331441

42 Gupta V, Gupta A, Kaur R, Narang S, Dogra MR: Efficacy of various laser wavelengths in the treatment of clinically significant macular edema in diabetics. Ophthalmic Surg Lasers 2001;32:397-405.

43 Friberg TR: Infrared micropulsed laser treatment for diabetic macular edema - subthreshold versus threshold lesions. Semin Ophthalmol 2001;16:19-24.

44 Luttrull JK, Musch DC, Mainster MA: Subthreshold diode micropulse photocoagulation for the treatment of clinically significant diabetic macular oedema. $\mathrm{Br}$ Ophthalmol 2005;89:74-80

45 Laursen ML, Moeller F, Sander B, Sjoelie AK Subthreshold micropulse diode laser treatment in diabetic macular oedema. Br J Ophthalmol 2004;88:1173-1179.

46 EDTRS: Grading diabetic retinopathy from stereoscopic color fundus photographs - an extension of the modified Airlie House classification. ETDRS report number 10. Early Treatment Diabetic Retinopathy Study Research Group. Ophthalmology 1991;98:786806.

47 Kinyoun J, Barton F, Fisher M, Hubbard L, Aiello L, Ferris F 3rd: Detection of diabetic macular edema: ophthalmoscopy versus photography - Early Treatment Diabetic Retinopathy Study Report Number 5. The ETDRS Research Group. Ophthalmology 1989;96:746-750; discussion 750-741.
48 Puliafito CA, Hee MR, Lin CP, Reichel E, Schuman JS, Duker JS, Izatt JA, Swanson EA, Fujimoto JG: Imaging of macular diseases with optical coherence tomography. Ophthalmology 1995;102:217-229.

49 Neubauer AS, Priglinger S, Ullrich S, Bechmann M, Thiel MJ, Ulbig MW, Kampik A: Comparison of foveal thickness measured with the retinal thickness analyzer and optical coherence tomography. Retina 2001;21: 596-601.

50 Neubauer AS, Priglinger S, Thiel MJ Bechmann M, Ulbig MW: Retinal maps: Retinal thickness analyzer (RTA) compared to optical coherence tomography (OCT). IOVS Suppl 2001;42:S793.

51 Polito A, Shah SM, Haller JA, Zimmer-Galler I, Zeimer R, Campochiaro PA, Vitale S: Comparison between retinal thickness analyzer and optical coherence tomography for assessment of foveal thickness in eyes with macular disease. Am J Ophthalmol 2002; 134:240-251

52 Shahidi M, Ogura Y, Blair NP, Rusin MM, Zeimer R: Retinal thickness analysis for quantitative assessment of diabetic macular edema. Arch Ophthalmol 1991;109:11151119.

53 Brown JC, Solomon SD, Bressler SB, Schachat AP, DiBernardo C, Bressler NM: Detection of diabetic foveal edema: contact lens biomicroscopy compared with optical coherence tomography. Arch Ophthalmol 2004;122:330-335

54 Browning DJ, McOwen MD, Bowen RM Jr., O'Marah TL: Comparison of the clinical diagnosis of diabetic macular edema with diagnosis by optical coherence tomography. Ophthalmology 2004;111:712-715.

55 Sanchez-Tocino H, Alvarez-Vidal A, Maldonado MJ, Moreno-Montanes J, Garcia-Layana A: Retinal thickness study with optical coherence tomography in patients with diabetes. Invest Ophthalmol Vis Sci 2002;43: 1588-1594

56 Giovannini A, Amato GP, Mariotti C, Ripa E: Diabetic maculopathy induced by vitreomacular traction: evaluation by optical coherence tomography (OCT). Doc Ophthalmol 1999;97:361-366.

57 Gallemore RP, Jumper JM, McCuen BW 2nd, Jaffe GJ, Postel EA, Toth CA: Diagnosis of vitreoretinal adhesions in macular disease with optical coherence tomography. Retina 2000;20:115-120.

58 Massin P, Duguid G, Erginay A, Haouchine B, Gaudric A: Optical coherence tomography for evaluating diabetic macular edema before and after vitrectomy. Am J Ophthalmol 2003;135:169-177.

59 Parolini B, Panozzo G, Gusson E, Pinackatt S, Bertoldo G, Rottini S, Pignatto S: Diode laser, vitrectomy and intravitreal triamcinolone: a comparative study for the treatment of diffuse non tractional diabetic macular edema. Semin Ophthalmol 2004;19:1-12.

60 Ferris F: Early photocoagulation in patients with either type I or type II diabetes. Trans Am Ophthalmol Soc 1996;94:505-537. 